\title{
Association Between TT Virus Infection and Cirrhosis in Liver Transplant Patients
}

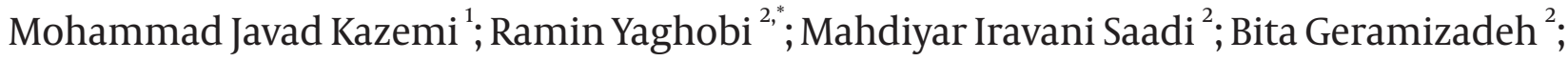 \\ Javad Moayedi $^{2}$ \\ ${ }^{1}$ Department of Biology, Ashkezar Branch, Islamic Azad University, Ashkezar, Yazd, IR Iran \\ ${ }^{2}$ Shiraz Transplant Research Center, Namazi Hospital, Shiraz University of Medical Sciences, Shiraz, IR Iran \\ ${ }^{*}$ Corresponding Author: Ramin Yaghobi, Shiraz Transplant Research Center, Namazi Hospital, Shiraz University of Medical Sciences, Shiraz, IR Iran. Tel: +98-7116474331, \\ E-mail: rayaviro@yahoo.com
}

Received: March 3, 2015; Revised: May 23, 2015; Accepted: August 19, 2015

\begin{abstract}
Background: Cirrhosis is one of the most severe liver complications, with multiple etiologies. The torque teno virus (TTV), also known as transfusion transmitted virus, which has a high incidence in the world population, is one of the possible increasing risk factors in patients with idiopathic fulminant hepatitis and cryptogenic cirrhosis.

Objectives: The aim of this study was to evaluate solitary and co-infection with TTV, in patients with cryptogenic and determined cause of cirrhosis.

Patients and Methods: In this cross-sectional study, 200 liver transplant patients were consecutively recruited between years 2007 and 2011. Patients were classified, based on recognition of the etiology of cirrhosis to determined ( $n=81)$ and cryptogenic $(n=119)$ patient groups. The existence of TTV infection was analyzed, using a semi-nested polymerase chain reaction method. The presence of hepatitis B virus (HBV) infective markers, including HBV DNA, hepatitis B surface antigen (HBsAg), hepatitis B e antigen (HBeAg), hepatitis B core antibody (HBcAb), and hepatitis B e antibody (HBeAb), was evaluated using qualitative polymerase chain reaction and enzyme linked immunosorbent assay protocols, respectively.

Results: The TTV infection was found in 37 of 200 (18.5\%) and 53 of $200(26.5 \%)$ plasma and tissue samples of studied liver transplanted patients, respectively. The TTV genomic DNA was found in 32 (26.9\%) and 28 (23.5\%) of 119 liver tissue and plasma samples of transplanted patients with cryptogenic cirrhosis, respectively. The genomic DNA of TTV was also diagnosed in $21(25.9 \%)$ and nine (11.1\%) of the 81 liver tissue and plasma samples of patients with determined cirrhosis, respectively. Significant associations were found between TTV infection with HBV molecular and immunologic infective markers, in liver transplanted patients, with determined and cryptogenic cirrhosis.

Conclusions: The diagnosis of the high frequency of solitary TTV and co-infection with HBV, in both liver transplanted patients with cryptogenic and determined cirrhosis, emphasized on the importance of TTV infection in the development of cirrhosis, especially in the cases of cryptogenic ones, prompting for further studies the confirm this agent in the etiology of determined cirrhosis.
\end{abstract}

Keywords: Liver Cirrhosis; Transplantation; Torque Teno Virus; Hepatitis B Virus

\section{Background}

Transfusion transmitted virus or torque teno virus (TTV) belongs to the Alphatorquevirus genus in the family of Anelloviridae (1). The TTV lacks an accurate definition of the biological nature and relationship to any human disease (2-4). Many epidemiological studies clearly point out the global distribution of the TTV in different populations, with various modes of propagation (5). This viral infection has been found in 1 - 18\% of blood donors and patients, who received blood and blood products (3-7).

The TTV can infect hepatocytes and most of its replication takes place in the liver $(8,9)$. Nevertheless, it has several pathogenic effects that specifically promote liver damage $(10,11)$. The irregular regeneration of hepatocytes was significantly higher in TTV infected patients $(12,13)$. However, the association between liver diseases and TTV infection seems conflicted (14-18). Most of earlier reports focused on the role of TTV infection in liver disorders and reported a possible association with cryptogenic liver disease and cirrhosis (14-17). Cryptogenic cirrhosis is a type of cirrhosis with unknown etiology and no history of alcoholism, or previous acute hepatitis, which cannot be explained by conventional clinical, laboratory and histological findings (14). Diagnostic requisites of cryptogenic cirrhosis have improved with progression of novel basic and technical knowledge. Cryptogenic cirrhosis is a heterogeneous advanced liver complication that needs to be defined clearly, like other defined liver cirrhosis $(17,19)$. Moreover, to determine the association between hepatitis B virus (HBV) and especially hepatitis $\mathrm{C}$ virus (HCV) especially, unde-

Copyright ( 2015, Kowsar Corp. This is an open-access article distributed under the terms of the Creative Commons Attribution-NonCommercial 4.0 International License (http://creativecommons.org/licenses/by-nc/4.0/) which permits copy and redistribute the material just in noncommercial usages, provided the original work is properly cited. 
fined or nonstandard viral infections, like HIV, the TTV and SEN virus may have a role in the pathogenesis of cryptogenic cirrhosis (19-31). The genomic DNA of TTV has been detected in near $15 \%$ of patients with cryptogenic cirrhosis, while in other studies the percent of detection remains controversial (32). The pathogenic role of nonstandard or occult hepatotrophic viruses, like TTV, in cryptogenic cirrhosis, is an important domain in the field of hepatitis and its complications, which needs to be evaluated in the vast majority of patients awaiting liver transplantation (33).

\section{Objectives}

The objective of this study was to evaluate the frequency of TTV infection in patients with cryptogenic cirrhosis, compared with cirrhosis of determined cases.

\section{Patients and Methods}

In this historical cohort study, 200 liver transplanted patients, who admitted to The Transplant Center at Namazi Hospital, Shiraz University of Medical Sciences, Shiraz, Iran, were consecutively recruited between years: 2007 and 2011. The etiology of cirrhosis was identified by an expert gastroenterologist team. Patients were classified based on recognition of the etiology of cirrhosis to determined $(n=81)$ and cryptogenic $(n=119)$ cirrhotic patients. Pathology based diagnosis of cryptogenic cirrhosis was also confirmed in 81 of 119 (68.1\%) liver transplanted patients, with clinical follow-up.

The EDTA treated blood and paraffin-embedded liver tissue samples that were already collected and saved in the Pathology Laboratory and Sample Bank of Shiraz Transplant Research Center, Shiraz, Iran, were used in this study. Local Shiraz University of Medical Sciences, Shiraz, Iran, Research Ethics Board Committee approved the study. The history of TTV infection was analyzed using the polymerase chain reaction (PCR) based molecular method. The history of the molecular and immunologic prevalence of HBV infective markers, including HBV DNA, hepatitis B surface antigen (HBsAg), hepatitis B e antigen (HBeAg), hepatitis B core antibody (HBcAb), and hepatitis B e antibody (HBeAb), were analyzed using PCR and enzyme linked immunosorbent assay (ELISA) based protocols.

\subsection{Molecular Analysis of Torque Teno Virus Infection}

The TTV genomic DNA was extracted from blood and paraffin-embedded liver tissue samples were collected from patients with cryptogenic and determined cirrhosis, using dinitrophenol (DNP) kit (Cinna Gen Inc., Tehran, Iran) according to manufacturer instruction. The presentation of TTV genomic DNA was analyzed in liver transplanted patient samples, using an in-house semi nested-PCR protocol, as previously described (34). The primer sequences used in simple and semi-nested PCR steps were included as: NG059, NG061 and NG063 that amplified 286 bp and 271 fragments of the N22 open reading frame 1 of TTV genome, respectively.

\subsection{Molecular Analysis of Hepatitis B Virus Infection}

The HBV genomic DNA was also diagnosed in liver transplanted patient samples, using a qualitative hepatitis $B$ virus PCR detection kit (Cinna Gen Inc., Tehran, Iran), as previously described (35).

\subsection{Hepatitis B Virus Immunological Markers}

The Hepatitis B Virus immunological markers, including $\mathrm{HBsAg}, \mathrm{HBcAb}, \mathrm{HBeAg}$ and $\mathrm{HBeAb}$, were evaluated in liver recipients with determined or cryptogenic cirrhosis, using third generation ELISA kits (Diapro Diagnostic Bioprobes Srl., Milan, Italy), according to manufacturer's instructions.

\subsection{Statistics}

Statistical analysis of the serum and tissue distribution of TTV in liver transplanted patients, with determined or cryptogenic cirrhosis, were performed using parametric and non-parametric methods, with SPSS software v.16 for Windows (SPSS Inc., Chicago, Il, USA). The P $\leq 0.05$ was accepted as statistically significant.

\section{Results}

\subsection{Patient's Profile}

Details of demographic data of studied liver transplanted patients, with determined or cryptogenic cirrhosis, are shown in Table 1 . The age range was 4 - 69, with mean of $38.48 \pm 14.43$ years old. A total of 139 (69.5\%) of the 200 patients were male and the rest of them 61 of them were female (Table 1 ).

\subsection{Torque Teno Virus and Risk Factors}

Significant associations were found between several demographic, laboratory and clinical indices, with an increased risk of TTV infection in clinical samples of studied liver transplanted patients. The age $(P=0.02)$, blood grouping $(\mathrm{P}=0.04)$, alanine transferase $(\mathrm{P}=0.01)$, asparagine transferase $(\mathrm{P}=0.05)$, blood urea nitrogen level $(\mathrm{P}=$ $0.04)$, and underlying disease ( $\mathrm{P}=0.01)$ were significantly associated with the presence of TTV infection, in plasma and liver tissue samples of liver transplanted patients, with determined and/or cryptogenic cirrhosis.

\subsection{Torque Teno Virus Infection}

The TTV infection was found in 37 (18.5\%) of 200 liver transplanted plasma samples. Based on gender, 27 (19.4\%) of 139 them were male and rest (10 of 61) were female. The TTV infection was also diagnosed in $53(26.5 \%)$ liver tissue samples, in which 39 (28.1\%) of 139 were male and $14(23.0 \%)$ of 61 were female. The TTV genomic DNA was found in $32(26.9 \%)$ and 28 (23.5\%) of 119 liver tissue and 
plasma samples. of liver transplanted patients with cryptogenic cirrhosis, respectively. The genomic DNA of TTV was also diagnosed in 21 (25.9\%) and nine (11.1\%) of 81 liver tissue and plasma samples, of patients with determines cirrhosis, respectively. The TTV genomic DNA was found in nine $(13.2 \%)$ of 68 patients, with determined cirrhosis who received liver transplant for HBV infection, as the underlying disease. However, TTV infection was not found in any transplant recipients with HCV infection, as underlying disease.

\subsection{Torque Teno Virus and Hepatitis B Virus Infection}

The association of TTV infection and diagnosis of HBV molecular and immunologic markers are presented in Table 2 .

\subsection{Torque Teno Virus and Hepatitis B Virus Ge- nomic DNA}

The HBV genomic DNA was found in 65 (52.0\%) of 125 patients, comprising of 48 (54.5\%) of 88 males and 17 (45.9\%) of 37 females. Also, the HBV genomic DNA was found in 23 (67.65\%) of 34 of all TTV infected liver transplanted plasma samples. The HBV DNA was found in 15 (57.6\%) of 26 and eight $(100 \%)$ of eight plasma samples of TTV infected liver transplanted patients with cryptogenic and determined cirrhosis, respectively. The HBV genomic DNA was found in 18 (54.5\%) of 33 of all TTV infected liver transplanted tissue samples, while it was also found in 13 (65\%) of 20 and five (38.4\%) of 13 tissue samples of TTV infected liver transplanted patients, with cryptogenic and determined cirrhosis, respectively. Significant associations were found between TTV infection and presence of HBV DNA in plasma samples of all liver transplanted patients $(\mathrm{P}=$ $0.02)$ and patients with determined cirrhosis $(\mathrm{P}=0.002)$, respectively (Table 2 ).

\subsection{Torque Teno Virus and Hepatitis B Surface Antigen}

The HBsAg was detected in 46 (37.7\%) of 122 patients, comprising of 32 (37.6\%) of 85 males and 14 (37.8\%) of 37 females. Of all the 34 TTV infected plasma samples of liver transplant patients, HBsAg was found in 21 (61.7\%). The HBsAg was found in 10 (38.4\%) of 26 and three (37.5\%) of eight plasma samples of TTV infected liver transplant patients, with cryptogenic and determined cirrhosis, respectively (Table 2 ). The HBsAg was found in 15 (45.5\%) of 33 of all TTV infected tissue samples of liver transplant patients. The 13 (65\%) of 20 and five $(38.4 \%)$ of 13 of the tissue samples of TTV infected liver transplanted patients, with cryptogenic and determined cirrhosis, were simultaneously co-infected with HBsAg positive, respectively (Table 2). The TTV infection and HBsAg were significantly concomitantly diagnosed in plasma samples of liver transplanted patients, with determined cirrhosis $(\mathrm{P}=0.02)$ (Table 2 ).

\subsection{Torque Teno Virus and Hepatitis B e Antigen}

The HBeAg was detected in 61 (50\%) of 122 patients, corresponding to 32 (37.6\%) of 85 males and 14 (37.8\%) of 37 females. The HBeAg was diagnosed in 19 (55.8\%) of 34 of all TTV infected plasma samples of liver transplant patients. The HBeAg was found in 13 (50\%) of 26 and six (75\%) of eight of the plasma samples of TTV infected liver transplanted patients, with cryptogenic and determined cirrhosis, respectively (Table 2). The HBeAg was found in 14 (42.4\%) of 33 of all TTV infected tissue samples of liver transplant patients. Nine (45\%) of 20 and five $(38.4 \%)$ of 13 of the tissue samples of TTV infected liver transplanted patients, with cryptogenic and determined cirrhosis, were simultaneously co-infected with HBsAg, respectively (Table 2). No significant association was found between TTV infection and diagnosis of HBeAg in plasma and tissue samples of liver transplanted patients, with cryptogenic and determined cirrhosis (Table 2 ).

\subsection{Torque Teno Virus and Hepatitis B Core}

\section{Antibody}

The HBcAb was detected in 38 (31.4\%) of 121 liver transplant patients, corresponding to 30 (35.3\%) of 85 males and eight $(22.2 \%)$ of 36 female. The HBcAb was diagnosed in 16 (47\%) of 34 of all TTV infected plasma samples. The HBcAb was detected in nine (34.6\%) of 26 and seven (87.5\%) of eight plasma samples of TTV infected patients, with cryptogenic and determined cirrhosis, respectively (Table 2 ). The HBcAb was found in six (18.1\%) of 33 tissue samples of all TTV infected patients. The HBcAb was diagnosed in one (5\%) of 20 and five (38.4\%) of 13 tissue samples of TTV infected recipients with cryptogenic and determined cirrhosis, respectively (Table 2). Significant associations were found between TTV infection and HBcAb in plasma and tissue samples of liver transplanted patients, with cryptogenic and determined cirrhosis (Table 2).

\subsection{Torque Teno Virus and Hepatitis B e Antibody}

The HBeAb was detected in 21(18.9\%) of 111 patients, representing 15 (71.43\%) of 21 males and six (18.2\%) of 21 females. The HBeAb was found in eight (23.5\%) of 34 plasma samples of all TTV infected patients. The HBeAb was detected in four (15.3\%) of 26 and four (50\%) of eight plasma samples of TTV infected patients, with cryptogenic and determined cirrhosis, respectively (Table 2). The HBeAb was found in six (18.1\%) of 33 tissue samples of all TTV infected patients. The HBeAb was diagnosed in only five (38.4\%) of 13 tissue samples of TTV infected recipients, with determined cirrhosis (Table 2). Also, HBeAb was significantly found in plasma samples of TTV infected liver transplanted patients, with cryptogenic cirrhosis $(\mathrm{P}=0.04)$ (Table 2 ). 
Kazemi MJ et al.

\begin{tabular}{lcc}
\hline \multicolumn{1}{l}{ Table 1. Demographic Parameters of Liver Transplanted Patients With Determined or Cryptogenic Cirrhosis ${ }^{\text {a }}$} \\
\hline Parameter & Cryptogenic Cirrhosis No. (\%) & Determined Cirrhosis No. (\%) \\
\hline Number of Patients & 119 & 81 \\
\hline HBV as Underlying Disease & Not Found & $68(84.0)$ \\
\hline HCV as Underlying Disease & Not Found & $13(16.0)$ \\
\hline Age of Donors & & $14-59$ \\
Age Range & $4-73$ & $35.99 \pm 13.67$ \\
Mean Age & $30 \pm 13.08$ & $17-63$ \\
\hline Age of Recipients & & $45.54 \pm 9.42$ \\
Age Range & $4-69$ & $63(77.8)$ \\
\hline Mean Age & $33.66 \pm 15.2$ & $18(22.2)$ \\
\hline Sex of Recipients & & $3.5(63 / 18)$ \\
\hline Male & $76(63.8)$ & \\
\hline Female & $43(36.1)$ & \\
\hline Male/Female & $1.7(76 / 43)$ & \\
\hline
\end{tabular}

a Abbreviations: HBV, Hepatitis B Virus; HCV, Hepatitis C Virus.

Table 2. Torque Teno Virus and Hepatitis B Virus Co-infection in Liver Transplanted Patients With Cryptogenic and Determined Cirrhosis $^{\text {a }}$

\begin{tabular}{|c|c|c|c|c|c|c|c|c|c|c|c|c|}
\hline \multirow{3}{*}{$\begin{array}{l}\text { TTV Co- } \\
\text { infection }\end{array}$} & \multicolumn{4}{|c|}{ Cryptogenic Cirrhosis } & \multicolumn{4}{|c|}{ Determined Cirrhosis } & \multicolumn{4}{|c|}{ Total Co-infection With TTV } \\
\hline & \multicolumn{2}{|c|}{$\begin{array}{c}\text { TTV-DNA in } \\
\text { Plasma }(n=26)\end{array}$} & \multicolumn{2}{|c|}{$\begin{array}{l}\text { TTV-DNA in Liver } \\
(\mathbf{n}=\mathbf{2 0})\end{array}$} & \multicolumn{2}{|c|}{$\begin{array}{l}\text { TTV-DNA in } \\
\text { Plasma }(n=8)\end{array}$} & \multicolumn{2}{|c|}{$\begin{array}{l}\text { TTV-DNA in Live } \\
(\mathbf{n}=13)\end{array}$} & \multicolumn{2}{|c|}{$\begin{array}{c}\text { TTV-DNA in } \\
\text { Plasma }(n=34)\end{array}$} & \multicolumn{2}{|c|}{$\begin{array}{l}\text { TTV-DNA in Liver } \\
\quad(n=33)\end{array}$} \\
\hline & No. (\%) & $\mathbf{P}$ & No. $(\%)$ & $\mathbf{P}$ & No. (\%) & $\mathbf{P}$ & No. (\%) & $\mathbf{P}$ & No. $(\%)$ & $\mathbf{P}$ & No. $(\%)$ & $\mathbf{P}$ \\
\hline $\begin{array}{l}\text { HBV } \\
\text { DNA in } \\
\text { Plasma }\end{array}$ & $15(57.6)$ & 0.33 & $13(65.0)$ & 0.15 & $8(100.0)$ & $0.002^{b}$ & $5(38.4)$ & 0.21 & $23(67.6)$ & $0.02^{b}$ & $18(54.5)$ & 0.44 \\
\hline HBsAg & $10(38.4)$ & 0.39 & $5(25.0)$ & 0.06 & $3(37.5)$ & 0.31 & $10(76.9)$ & $0.02^{b}$ & $21(61.7)$ & 0.54 & $15(45.5)$ & 0.12 \\
\hline HBcAb & $9(34.6)$ & $0.02^{b}$ & $1(5.0)$ & $0.05^{b}$ & $7(87.5)$ & $0.05^{b}$ & $5(38.4)$ & 0.10 & $16(47.0)$ & $0.01^{b}$ & $6(18.1)$ & $0.04^{b}$ \\
\hline HBeAg & $13(50.0)$ & 0.5 & $9(45.0)$ & 0.47 & $6(75.0)$ & 0.5 & $5(38.4)$ & 0.26 & $19(55.8)$ & 0.44 & $14(42.4)$ & 0.43 \\
\hline HBeAb & $4(15.3)$ & $0.04^{b}$ & $0(0.0)$ & 0.16 & $4(50.0)$ & 0.3 & $5(38.4)$ & 0.64 & $8(23.5)$ & 0.11 & $5(15.1)$ & 0.43 \\
\hline
\end{tabular}

a Abbreviations: HBcAb, Hepatitis B Core Antibody; HBeAb, Hepatitis B e Antibody; HBeAg, Hepatitis B e Antigen; HBsAg, Hepatitis B Surface Antigen; HBV, Hepatitis B Virus; TTV, Torque Teno Virus.

b $\mathrm{P} \leq 0.05$ was accepted as statistically significant.

\section{Discussion}

Knowledge about TTV is growing fast, although several fundamental aspects remain unclear. The worldwide prevalence and clinical significance of TTV are being evaluated. A higher frequency of TTV infection was found in patients with idiopathic fulminant hepatitis and with cryptogenic cirrhosis (36). The cause and effect relationship of TTV infection with liver disease, especially the determinative role on introducing or promoting cirrhosis, remains controversial (37-39). This study was enrolled based on limited information exist about the role of TTV infection in pathogenesis of cryptogenic versus determined cirrhosis in liver transplant patients. In this report, TTV infection was found in $18.5 \%$ and $26.5 \%$ of liver transplanted plasma and tissue samples, respectively. The TTV genomic DNA was found separately in $26.9 \%$ vs.
$23.5 \%$ and $25.9 \%$ vs. $11.1 \%$ of liver tissue and plasma samples of transplant patients with cryptogenic and determined cirrhosis, respectively. Similarly, in other previous reports, the importance of this viral infection in promoting liver damage was also studied. The TTV infection was found in Japanese patients with cirrhosis, in which the etiologic role of other defined hepatitis viruses was ruled out (40). Multiple speculations suggested that TTV can induce liver damage. The potential of TTV infection to cause hepatitis was backed-up by the association of TT viremia, with liver enzyme elevation (41-43). Although an elevated load of TTV genomic DNA was found in serum and liver tissue of patients with hepatitis, several reports have tracked this viral infection in patients without hepatitis (8). Earlier studies have revealed TTV infection in chil- 
dren with cryptogenic hepatitis, chronic HBV hepatitis, and also, in children without hepatitis $(44,45)$. Variable frequencies of TTV infection that were reported in patients with leukemia have revealed a different spectrum of liver involvement, ranging from minimal elevation of liver enzymes to severe hepatic failure (8). Two characteristics emphasize on the potential role of TTV in the pathogenesis of liver disease. The first is the observation of the higher load of TTV genome in liver disordered patients, without presence of non-A-G hepatitis viruses (11). The second regards the fact that TTV becomes undetectable in viral infected patients, with normalized levels of liver enzymes $(24,46)$. Also, this study analyzed the possible associations between different HBV infective markers with TTV infection. The HBV DNA was found in $57.6 \%$ vs. $100 \%$ and $65 \%$ vs. $38.4 \%$ of plasma and tissue samples of TTV infected liver transplant patients, with cryptogenic and determined cirrhosis, respectively. Significant associations were found between TTV infection and presence of HBV DNA in plasma samples of liver transplanted patients, with determined cirrhosis. The HBsAg was found in $38.4 \%$ vs. $37.5 \%$ and $65 \%$ vs. $38.4 \%$ of plasma and tissue samples of TTV infected liver transplant patients, with cryptogenic and determined cirrhosis, respectively. The TTV infection and HBsAg were significantly correlated in plasma samples of liver transplanted patients, with determined cirrhosis. The HBeAg was also found in 50\% vs. $75 \%$ and $45 \%$ vs. $38.4 \%$ of plasma and tissue samples of TTV infected liver transplant patients with cryptogenic and determined cirrhosis, respectively. The HBeAb was detected in $15.3 \%$ vs. $50 \%$ and none vs. $38.4 \%$ of plasma and tissue samples of TTV infected patients, with cryptogenic and determines cirrhosis, respectively. The HBeAb was significantly found in plasma samples of TTV infected liver transplant patients, with cryptogenic cirrhosis.

The HBcAb was detected in $34.6 \%$ vs. $87.5 \%$ and $5.0 \%$ vs. $38.4 \%$ of plasma and tissue samples of TTV infected patients, with cryptogenic and determined cirrhosis, respectively. Significant associations were found between TTV infection and HBcAb in plasma and tissue samples of all liver transplanted patients, with cryptogenic and determined cirrhosis. The co-infection of TTV with other important hepatitis viruses was also reported earlier. This co-infectivity was found in different reports, as follows: $73 \%$ with Hepatitis C Virus (HCV) and $91 \%$ with HBV infections (47), 53.8\% with HCV and $47.3 \%$ with HBV infections, respectively (48). Also $34 \%$ and $6 \%$ of patients with chronic HBV infection were diagnosed with TTV infection, using two different primers sets (49). In other earlier reports, the importance of the relationships between co-infectivity of TTV and HCV with increased severity of liver diseases $(50,51)$. Moreover, high TTV load is associated with occurrence of hepatocellular carcinoma in HCV infected patients (39).

The diagnosis of high frequency of solitary TTV infection and, also, significant association of TTV with different infective markers of HBV were confirmed in both liver transplanted patients with cryptogenic and determined cirrhosis. These results suggest the increasing importance of TTV infection in the development of cirrhosis and a particular interest should be given to cryptogenic forms, which should be performed in further studies.

\section{Authors' Contributions}

Study concept and design: Mohammad Javad Kazemi, Ramin Yaghobi, Bita Geramizadeh. Analysis and interpretation of data: Mohammad Javad Kazemi, Ramin Yaghobi, Mahdiyar Iravani Saadi, Javad Moayedi. Drafting of the manuscript: Mohammad Javad Kazemi, Ramin Yaghobi, Bita Geramizadeh, Mahdiyar Iravani Saadi. Critical revision of the manuscript for important intellectual content: Mohammad Javad Kazemi, Ramin Yaghobi, Bita Geramizadeh, Mahdiyar Iravani Saadi. Statistical analysis: Ramin Yaghobi, Mahdiyar Iravani Saadi.

\section{Funding/Support}

The authors especially thanks to Ashkezar Branch of Islamic Azad University and Shiraz University of Medical Sciences for their supports and laboratory facilities.

\section{References}

1. Biagini P. Classification of TTV and related viruses (anelloviruses). Curr Top Microbiol Immunol. 2009;331:21-33.

2. Okamoto H, Takahashi M, Nishizawa T, Tawara A, Sugai Y, Sai T, et al. Replicative forms of TT virus DNA in bone marrow cells. Biochem Biophys Res Commun. 2000;270(2):657-62.

3. Hino S, Miyata H. Torque teno virus (TTV): current status. Rev Med Virol.2007; 17(1):45-57.

4. Okamoto H. History of discoveries and pathogenicity of TT viruses. Curr Top Microbiol Immunol. 2009;331:1-20.

5. Zheng MY, Lin Y, Li DJ, Ruan HB, Chen Y, Wu TT. [TTV and HPV coinfection in cervical smears of patients with cervical lesions in littoral of Zhejiang province]. Zhonghua Shi Yan He Lin Chuang Bing Du Xue Za Zhi. 2010;24(2):110-2.

6. Maeda M, Hamada H, Tsuda A, Kaneko K, Fukunaga Y. High rate of TTV infection in multitransfused patients with pediatric malignancy and hematological disorders. Am JHematol.2000;65(1):41-4.

7. Maggi F, Pistello M, Vatteroni M, Presciuttini S, Marchi S, Isola P, et al. Dynamics of persistent TT virus infection, as determined in patients treated with alpha interferon for concomitant hepatitis C virus infection.J Virol. 2001;75(24):11999-2004.

8. Zhong S, Yeo W, Tang M, Liu C, Lin XR, Ho WM, et al. Frequent detection of the replicative form of TT virus DNA in peripheral blood mononuclear cells and bone marrow cells in cancer patients. J Med Virol. 2002;66(3):428-34.

9. Suzuki F, Chayama K, Tsubota A, Akuta N, Someya T, Kobayashi M, et al. Pathogenic significance and organic virus levels in patients infected with TT virus. Intervirology. 2001;44(5):291-7.

10. Hu ZJ, Lang ZW, Zhou YS, Yan HP, Huang DZ, Chen WR, et al. Clinicopathological study on TTV infection in hepatitis of unknown etiology. World J Gastroenterol. 2002;8(2):288-93.

11. Bendinelli M, Pistello M, Maggi F, Fornai C, Freer G, Vatteroni ML. Molecular properties, biology, and clinical implications of TT virus, a recently identified widespread infectious agent of humans. Clin Microbiol Rev. 2001;14(1):98-113.

12. Moriyama M, Matsumura H, Shimizu T, Shioda A, Kaneko M, Miyazawa K, et al. Histopathologic impact of TT virus infection on the liver of type $\mathrm{C}$ chronic hepatitis and liver cirrhosis in Japan. $J$ Med Virol. 2001;64(1):74-81.

13. Camci C, Guney C, Balkan A, Buyukberber N, Buyukberber S, Kadayifci A, et al. The prevalence of TT virus in cancer patients. New 
Microbiol. 2002;25(4):463-8.

14. Czaja AJ, Carpenter HA, Santrach PJ, Moore SB, Homburger HA. The nature and prognosis of severe cryptogenic chronic active hepatitis. Gastroenterology.1993;104(6):1755-61.

15. Baeres M, Herkel J, Czaja AJ, Wies I, Kanzler S, Cancado EL, et al. Establishment of standardised SLA/LP immunoassays: specificity for autoimmune hepatitis, worldwide occurrence, and clinical characteristics. Gut. 2002;51(2):259-64.

16. Czaja AJ, Donaldson PT, Lohse AW. Antibodies to soluble liver an tigen/liver pancreas and HLA risk factors for type 1 autoimmune hepatitis. Am J Gastroenterol. 2002;97(2):413-9.

17. Czaja AJ, Pfeifer KD, Decker RH, Vallari AS. Frequency and significance of antibodies to a sialoglycoprotein receptor in type 1 autoimmune hepatitis. Dig Dis Sci. 1996;41(9):1733-40.

18. Battle WM, Matarazzo SA, Selhat GF, Catalano E. Alpha-1-antitrypsin deficiency-a cause of cryptogenic liver disease in the elderly J Clin Gastroenterol. 1982;4(3):269-73.

19. Marmur J, Bergquist A, Stal P. Liver transplantation of patients with cryptogenic cirrhosis: clinical characteristics and outcome. Scand J Gastroenterol. 2010;45(1):60-9.

20. Nayak NC, Vasdev N, Saigal S, Soin AS. End-stage nonalcoholic fatty liver disease: evaluation of pathomorphologic features and relationship to cryptogenic cirrhosis from study of explant livers in a living donor liver transplant program. Hum Pathol. 2010;41(3):425-30.

21. Duclos-Vallee JC, Yilmaz F, Johanet C, Roque-Afonso AM, Gigou $\mathrm{M}$, Trichet $\mathrm{C}$, et al. Could post-liver transplantation course be helpful for the diagnosis of so called cryptogenic cirrhosis? Clin Transplant. 2005;19(5):591-9.

22. Greeve M, Ferrell L, Kim M, Combs C, Roberts J, Ascher N, et al. Cirrhosis of undefined pathogenesis: absence of evidence for unknown viruses or autoimmune processes. Hepatology. 1993;17(4):593-8.

23. Irshad M, Mandal K, Singh S, Agarwal SK. Torque teno virus infection in hemodialysis patients in North India. Int Urol Nephrol. 2010;42(4):1077-83

24. Charlton MR, Kondo M, Roberts SK, Steers JL, Krom RA, Wiesner RH. Liver transplantation for cryptogenic cirrhosis. Liver Transp Surg. 1997;3(4):359-64.

25. Piaggio F, Dodi F, Bottino G, Andorno E, Gentile R, Ferrari C, et al. Torque Teno Virus--cause of viral liver disease following liver transplantation: a case report. Transplant Proc. 2009;41(4):1378-9.

26. Tsuge M, Noguchi C, Akiyama R, Matsushita M, Kunihiro K, Tanaka S, et al. G to A hypermutation of TT virus. Virus Res. 2010;149(2):211-6.

27. Asim M, Singla R, Gupta RK, Kar P. Clinical \& molecular characterization of human TT virus in different liver diseases. Indian J Med Res. 2010;131:545-54.

28. Akiba J, Umemura T, Alter HJ, Kojiro M, Tabor E. SEN virus: epidemiology and characteristics of a transfusion-transmitted virus. Transfusion. 2005;45(7):1084-8.

29. Omar M, El-Din SS, Fam N, Diab M, Shemis M, Raafat M, et al. SEN virus infection in Egyptian patients with chronic hepatitis C and patients undergoing hemodialysis. Medscape J Med. 2008;10(12):290.

30. Loutfy SA, Hafez MM, Massoud WA, Fotuh NA, Moneer MM, Zaghloul HS. SEN virus infection in Egyptian patients undergoing maintenance hemodialysis: prevalence and clinical importance. J Microbiol Immunol Infect. 2009;42(6):464-70.

31. Karimi-Rastehkenari A, Bouzari M. High frequency of SEN virus infection in thalassemic patients and healthy blood donors in Iran. Virol J. 2010;7:1.

32. Charlton M, Adjei P, Poterucha J, Zein N, Moore B, Therneau T, et al. TT-virus infection in North American blood donors, patients with fulminant hepatic failure, and cryptogenic cirrhosis. Hepatology.1998;28(3):839-42.

33. Czaja AJ. Cryptogenic chronic hepatitis and its changing guise in adults. Dig Dis Sci. 2011;56(12):3421-38.

34. Bagheri K, Yaghobi R, Karimi MH, Mohammadi B, Ramzi M. Study the prevalence of torque teno (TT) virus infectionin patients with hematological malignancies. AJMR . 2012;6(31):6081-5.

35. Hejr S, Karimi MH, Yaghobi R, Kamali-Sarvestani E, Geramizadeh B, Roozbeh J. Association of IL-17, IL-21, and IL-23R gene polymorphisms with HBV infection in kidney transplant patients. Viral Immunol. 2013;26(3):201-6.

36. Gimenez-Barcons M, Forns X, Ampurdanes S, Guilera M, Soler M Soguero C, et al. Infection with a novel human DNA virus (TTV) has no pathogenic significance in patients with liver diseases. $J$ Hepatol.1999;30(6):1028-34.

37. Tangkijvanich P, Anukulkarnkusol N, Suwangool P, Lertmaharit S, Hanvivatvong O, Kullavanijaya P, et al. Clinical characteristics and prognosis of hepatocellular carcinoma: analysis based on serum alpha-fetoprotein levels. J Clin Gastroenterol. 2000;31(4):302-8.

38. Tokita H, Murai S, Kamitsukasa H, Yagura M, Harada H, Takahashi $\mathrm{M}$, et al. High TT virus load as an independent factor associated with the occurrence of hepatocellular carcinoma among patients with hepatitis $\mathrm{C}$ virus-related chronic liver disease. J Med Virol. 2002;67(4):501-9.

39. Mirzaee M, Yaghobi R, Ramzi M, Roshan Nia M. The prevalence of molecular and immunologic infective markers of hepatitis viruses in patients with hematological malignancies. Mol Biol Rep. 2012;39(2):1217-23.

40. Okamoto H. Molecular cloning and characterization of a novel DNA virus (TTV) associated with posttransfusion hepatitis of unknown etiology. Hepatol Res.1998;10(1):1-16.

41. Nishizawa T, Okamoto H, Konishi K, Yoshizawa H, Miyakawa Y, Mayumi M. A novel DNA virus (TTV) associated with elevated transaminase levels in posttransfusion hepatitis of unknown etiology. Biochem Biophys Res Commun. 1997;241(1):92-7.

42. Fujiwara T, Iwata A, Iizuka H, Tanaka T, Okamoto H. Transfusion transmitted virus. Lancet.1998;352(9136):1310-1.

43. Chen BP, Rumi MG, Colombo M, Lin YH, Ramaswamy L, Luna J, e al. TT virus is present in a high frequency of Italian hemophilic patients transfused with plasma-derived clotting factor concentrates. Blood.1999;94(12):4333-6.

44. Ergunay K, Gurakan F, Usta Y, Yuce A, Karabulut HO, Ustacelebi S. Detection of TT virus (TTV) by three frequently-used PCR methods targeting different regions of viral genome in children with cryptogenic hepatitis, chronic B hepatitis and hbs carriers. Turk Pediatr. 2008;50(5):432-7.

45. Hsieh SY, Wu YH, HoYP, Tsao KC, Yeh CT, LiawYF. High prevalence of TT virus infection in healthy children and adults and in patients with liver disease in Taiwan. J Clin Microbiol. 1999;37(6):1829-31.

46. Leary TP, Erker JC, Chalmers ML, Desai SM, Mushahwar IK. Improved detection systems for TT virus reveal high prevalence in humans, non-human primates and farm animals. J Gen Virol. 1999;80 ( Pt 8):2115-20.

47. Savas MC, Guney C, Kadayifci A, Balkan A, Koruk M, Kubar A, et al. High prevalence of transfusion-transmitted virus infection in patients with chronic liver diseases in an endemic area of hepatitis B and C virus. Med Princ Pract. 2003;12(3):176-9.

48. Verdi H. Comparision of two different primer sets for PCR detection of transfusion transmitted virus DNA in blood donors, hemodialysis patients and patients with thalassemia major chronic HBV and HCV infection. J Hepatol. 2001;34:163.

49. Yamamoto T, Kajino K, Ogawa M, Gotoh I, Matsuoka S, Suzuki $\mathrm{K}$, et al. Hepatocellular carcinomas infected with the novel TT DNA virus lack viral integration. Biochem Biophys Res Commun. 1998;251(1):339-43.

50. Abraham P, John GT, Raghuraman S, Radhakrishnan S, Thomas $\mathrm{PP}$, Jacob CK, et al. GB virus $\mathrm{C} /$ hepatitis $\mathrm{G}$ virus and TT virus infections among high risk renal transplant recipients in India. J Clin Virol. 2003;28(1):59-69.

51. Fiordalisi G, Zanella I, Mantero G, Bettinardi A, Stellini R, Paraninfo $G$, et al. High prevalence of GB virus $C$ infection in a group of Italian patients with hepatitis of unknown etiology.J Infect Dis. 1996;174(1):181-3. 